\title{
Hybrid endoscopic submucosal dissection using a full-thickness resection device allows en bloc resection of a large adenoma deeply invading the appendix
}

Endoscopic full-thickness resection using a full-thickness resection device (FTRD) (Ovesco; Tübingen, Germany) was introduced in 2014 and is mainly used for small colonic laterally spreading tumors (LSTs) with important fibrotic component, non-lifting after submucosal injection, or superficial recurrent lesions located at or near a surgical anastomosis. It has an $81 \% \mathrm{R} 0$ resection rate for lesions $\leq 2 \mathrm{~cm}$, with a $10 \%$ rate of adverse events $[1,2]$. The main limitations are large tumor size and proximal colonic lesions, as the FTRD cap is $23 \mathrm{~mm}$ in length, which sometimes makes cecal intubation difficult. The most important risks are bleeding, trapping of pericolonic organs when sucking the lesions into the cap, and luminal stenosis due to the clip [3].

We present the case of a large LST invading the appendectomy site. Standard resection using the FTRD was not possible because the lesion ( $>$ Fig. 1; > Video 1) was too large $(40 \mathrm{~mm})$ to fit into the cap, so we first performed a circumferential incision and endoscopic submucosal dissection using the clip and rubber-

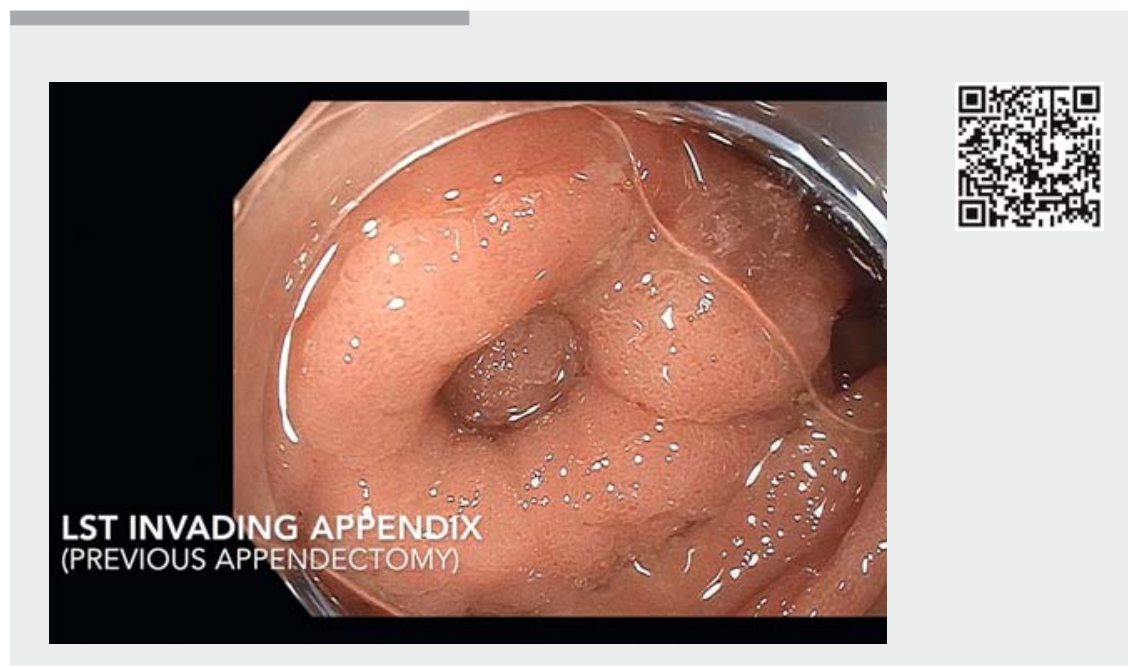

$\checkmark$ Video 1 A hybrid full-thickness resection is performed on a large laterally spreading tumor invading the appendectomy site. The lesion is first incised circumferentially then endoscopic submucosal dissection is performed using the clip and rubber-band traction method, which is followed by resection using the full-thickness resection device and a polypectomy snare.

band strategy ( $>$ Fig. 2 ) $[4,5]$. We then used the FTRD system to trap the dissected corolla into the cap (\$Fig.3). The clip was placed safely around the le- sion and sectioning was performed using a standard polypectomy snare (failure of cutting with 13-mm FTRD integrated snare).
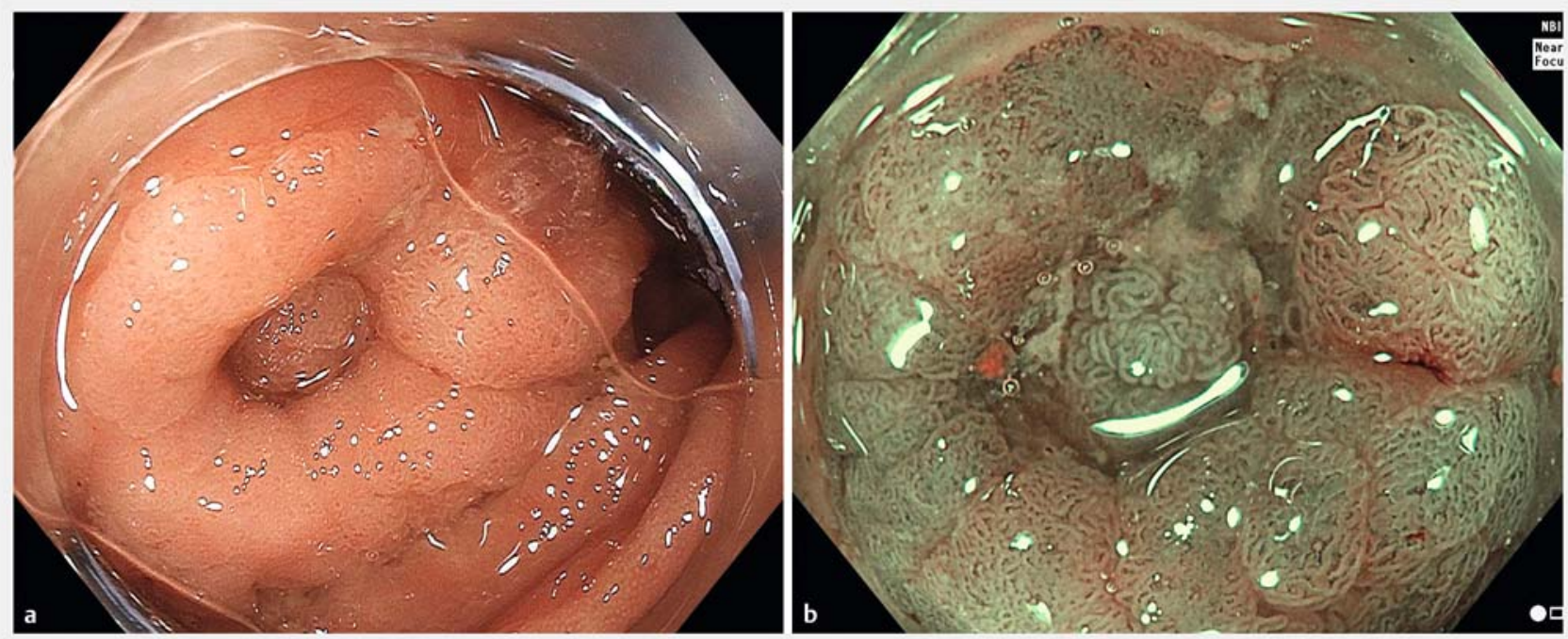

Fig. 1 Appearance of a large laterally spreading tumor invading the appendectomy site that was treated by hybrid full-thickness resection on: a white-light endoscopy; b narrow-band imaging. 


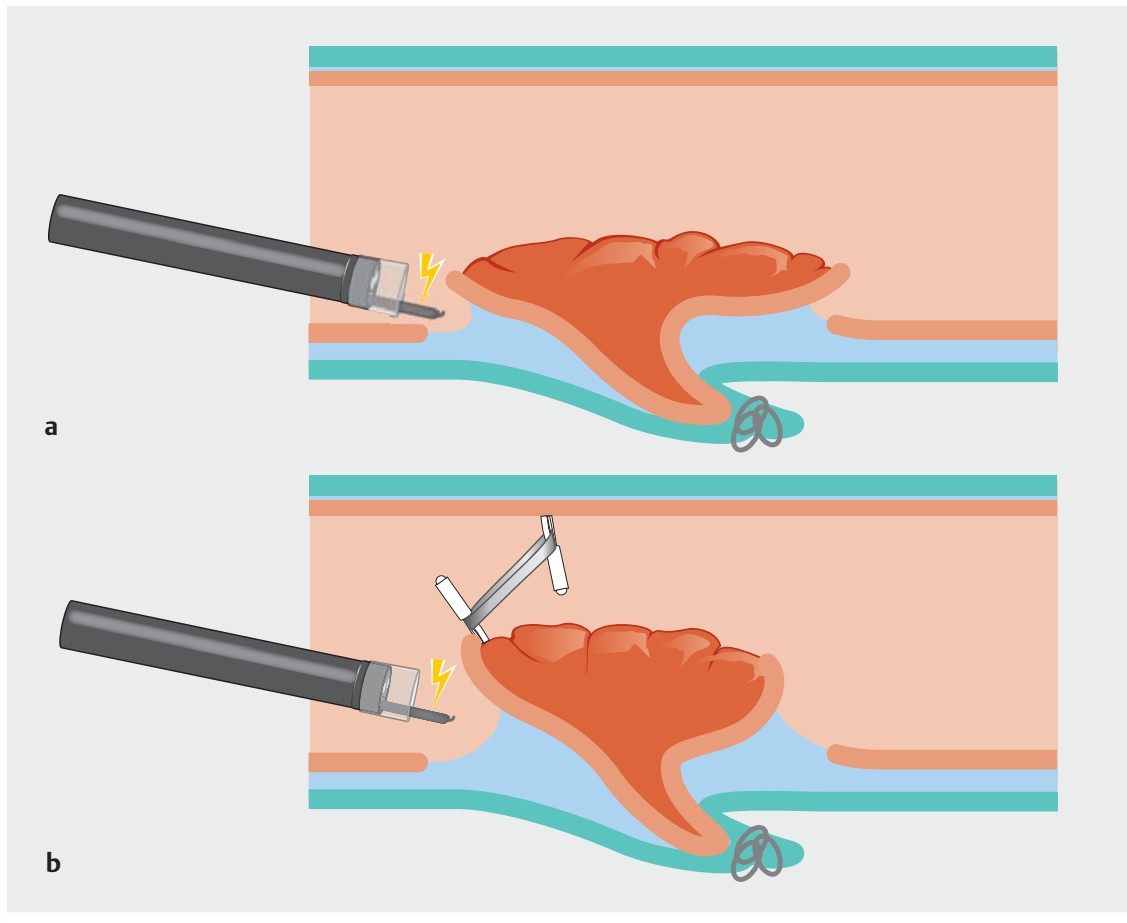

Fig. 2 Schematic of the first stage of the procedure, showing: a circumferential incision; b endoscopic submucosal dissection using clip traction.

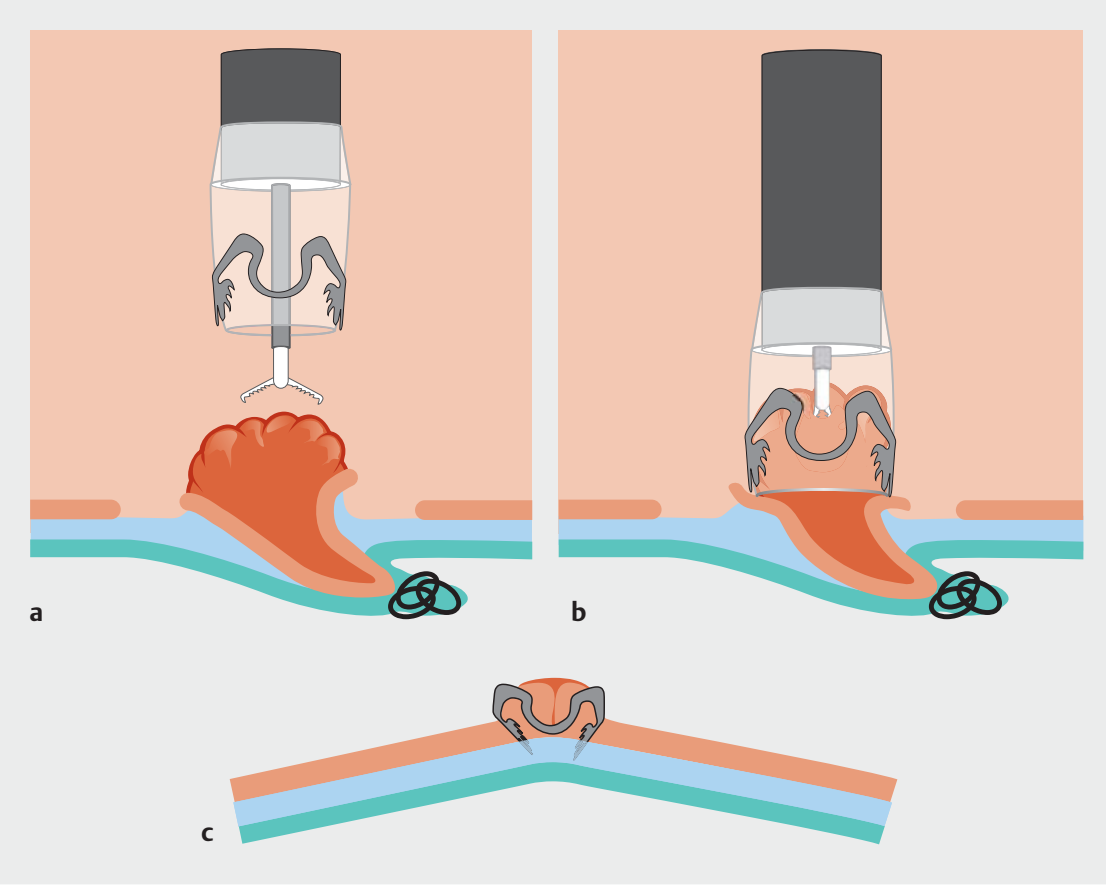

- Fig. 3 Schematic of the second stage of the procedure, illustrating: $\mathbf{a}, \mathbf{b}$ resection using the full-thickness resection device; $\mathbf{c}$ the mucosal view after full-thickness resection with the clip in place.

The resected specimen ( $>$ Fig. 4 ) was examined histopathologically and showed an RO full-thickness resection of a low grade dysplastic adenomatous lesion.
To our knowledge, this is the first case of resection using hybrid dissection and an FTRD. This new strategy may allow resection of large fibrous superficial lesions that are not accessible to standard endoscopic resection techniques. Our case is particularly interesting as we removed a lesion invading the appendectomy site en bloc with free margins. Future studies are required to validate this new hybrid resection technique.

Endoscopy_UCTN_Code_TTT_1AQ_2AD

Competing interests

None

The authors

Alexandru Lupu ${ }^{1,2}$, Jérémie Jacques ${ }^{3}$, Jérôme Rivory ${ }^{1}$, Jean-Christophe Saurin ${ }^{1}$, Florian Rostain ${ }^{1}$, Thierry Ponchon ${ }^{1,4}$, Mathieu Pioche ${ }^{1,4}$

1 Department of Endoscopy and Gastroenterology, Pavillion L, Eduard Herriot Hospital, Lyon, France

2 Department of Endoscopy and Gastroenterology, Fundeni Hospital, Bucharest, Romania

3 Department of Endoscopy and Gastroenterology, Limoges University Hospital, Limoges, France

4 Inserm U1032 LabTau, Lyon, France

Corresponding author

Mathieu Pioche, MD

Endoscopy unit - Digestive Disease department, Pavilion L - Edouard Herriot Hospital, 69437 Lyon, France mathieu.pioche@chu-lyon.fr

References

[1] Schmidt A, Bauerfeind P, Gubler C et al. Endoscopic full-thickness resection in the colorectum with a novel over-the-scope device: first experience. Endoscopy 2015; 47 : $719-725$

[2] Schurr MO, Baur FE, Krautwald M et al. Endoscopic full-thickness resection and clip defect closure in the colon with the new FTRD system: experimental study. Surg Endosc 2015; 29: 2434-2441 

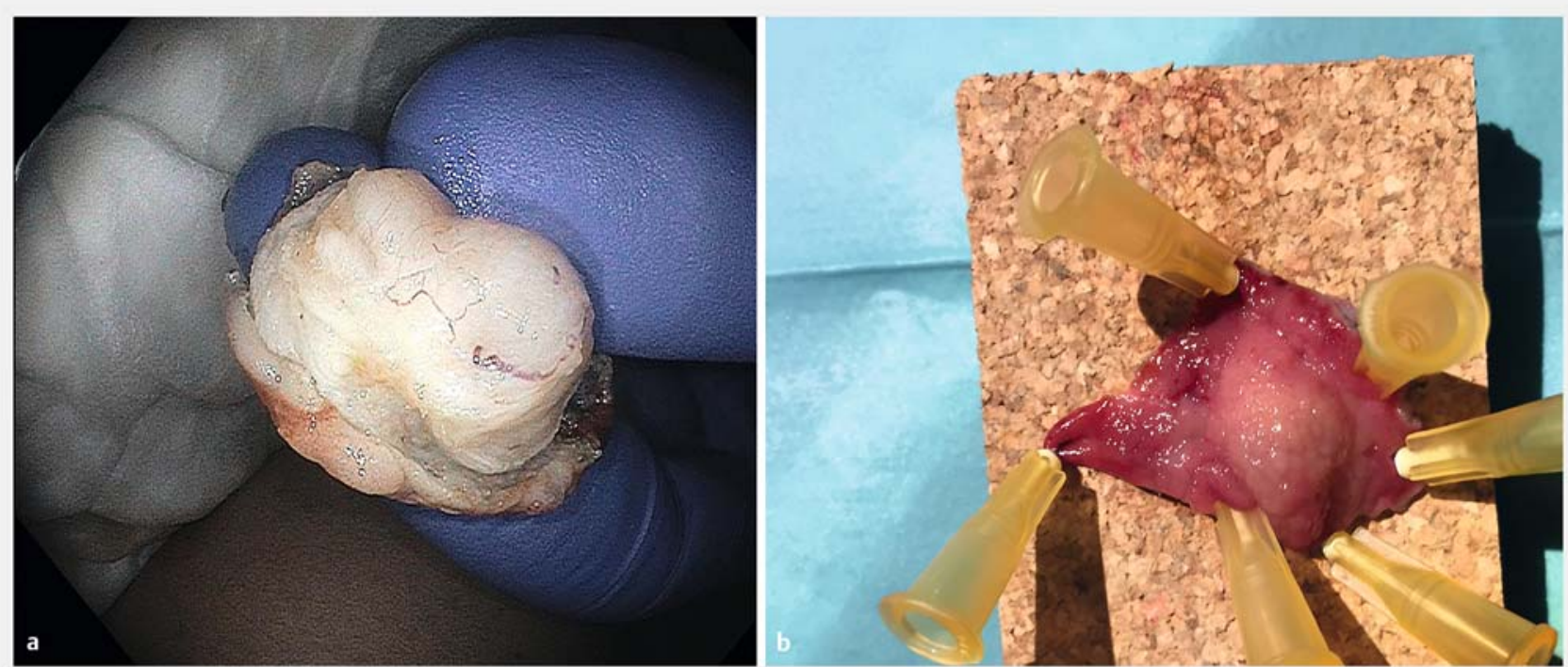

Fig. 4 Photographs of: a the specimen removed by the full-thickness resection device; $\mathbf{b}$ the specimen after placement on a cork board.

[3] Wedi E, Orlandini B, Gromski M et al. Fullthickness resection device for complex colorectal lesions in high-risk patients as a last-resort endoscopic treatment: initial clinical experience and review of the current literature. Clin Endosc 2018; 51: 103-108

[4] Utzeri E, Jacques ], Charissoux A et al. Traction strategy with clips and rubber band allows complete en bloc endoscopic submucosal dissection of laterally spreading tumors invading the appendix. Endoscopy 2017; 49: 820-822

[5] Jacques ], Charissoux A, Legros R et al. Double-clip counter-traction using a rubber band is a useful and adaptive tool for colonic endoscopic submucosal dissection. Endoscopy 2018; 50: 179-181

\section{Bibliography}

DOI https://doi.org/10.1055/a-0651-0393

Published online: 8.8.2018

Endoscopy 2018; 50: E296-E298

(c) Georg Thieme Verlag KG

Stuttgart · New York

ISSN 0013-726X

\section{ENDOSCOPY E-VIDEOS \\ https://eref.thieme.de/e-videos}

回回 Endoscopy E-Videos is a free

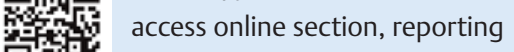
回然: on interesting cases and new techniques in gastroenterological endoscopy. All papers include a high quality video and all contributions are freely accessible online.

This section has its own submission website at https://mc.manuscriptcentral.com/e-videos 